\title{
Quantitative sensory testing in elderly: longitudinal study
}

\author{
Teste sensitivo quantitativo em idosos: estudo longitudinal \\ Luciana Alvarenga da Silva ${ }^{1}$, Omar Jaluul², Manoel Jacobsen Teixeira ${ }^{3}$, José Tadeu Tesseroli de Siqueira ${ }^{4}$, \\ Wilson Jacob Filho5, Silvia Regina Dowgan Tesseroli de Siqueira ${ }^{6}$
}

\begin{abstract}
Objective: To evaluate elderly patients in a geriatric service, along with their sensory characteristics and their association with clinical aspects. Methods: This was a descriptive longitudinal study. We enrolled 36 healthy participants of both sexes in this study. The following instruments were used and evaluations performed: clinical evaluation, Mini-Mental State Exam, and quantitative sensory testing. Results: During the follow-up, there was reduction of mean corpuscular volume at each evaluation $(p<0.001)$ and significant increase in mean corpuscular hemoglobin concentration ( $p<0.001)$. There was an increase of the olfactory $(p<0.001)$, salty $(p=0.024)$, sour $(p=0.020)$, bitter $(p=0.001)$, facial cold $(p=0.019)$, hand cold $(p=0.004)$, facial tactile $(p<0.001)$, hand tactile $(p=0.012)$ and facial vibration $(p=$ 0.018 ) thresholds. Previous existing morbidities were associated with sensitivity changes in the individuals in this sample. Conclusion: This longitudinal study suggests that the loss of sensitivity with aging may be associated with the presence of morbidities in elders.
\end{abstract}

Keywords: Aging; sensory thresholds; aged; taste; smell.

\section{RESUMO}

Objetivo: Avaliar pacientes idosos em um serviço de geriatria, juntamente com as características sensitivas e sua associação com aspectos clínicos. Métodos: Este é um estudo longitudinal descritivo. Foram avaliados 36 sujeitos saudáveis de ambos os sexos. Os seguintes instrumentos e avaliações foram realizados: Avaliação clínica, Mini Exame de Estado Mental (Mini-Mental) e testes sensitivos quantitativos. Resultados: Durante o acompanhamento houve redução do volume corpuscular médio (VCM) em cada avaliação ( $P<0,001)$ e aumento significativo das concentrações de hemoglobina corpuscular média (CHCM) $(P<0,001)$. Houve aumento dos limiares olfativos ( $p<0,001)$, salgado $(p=0,024)$, azedo $(p=0,020)$, amargo $(p=0,001)$, frio face $(p=0,019)$, frio mão $(p=0,004)$, tato face $(p<0,001)$, tato mão $(p=0.012)$ e vibração face $(p=0,018)$. Morbidades prévias foram associadas às alterações de sensibilidade nos indivíduos desta amostra. Conclusão: Este estudo longitudinal sugere que a perda de sensibilidade no envelhecimento pode estar associada à presença de morbidades em idosos.

Palavras-chave: Envelhecimento; limiar sensorial; idoso; paladar; olfato.

Many countries are experiencing an aging population ${ }^{1}$. Among the implications of the high rate of growth in the number of elderly people is the increase in age-related morbidities. Aging is considered the main risk factor for the occurrence of diseases ${ }^{2}$.

Human aging is defined as a summation of molecular, cellular and tissue changes resulting over the years in decreased physiological capacities and a greater predisposition to diseases ${ }^{3}$. However, this process is complex and still poorly understood ${ }^{4}$.
Studies have shown that advancing age is followed by changes in special and general sensitivities ${ }^{5,6}$. The human aging process is followed by gradually decreasing sensitivity $^{5,6,7,8}$ and changes in olfactory loss may precede the appearance of neurodegenerative diseases such as Alzheimer's disease and Parkinson's disease ${ }^{9,10}$. In addition, somatosensory abnormalities are found in patients with diabetes mellitus ${ }^{11}$, and are associated with the onset of diabetic neuropathy ${ }^{11,12}$.

\footnotetext{
1 Universidade de São Paulo, Departamento de Neurologia, São Paulo SP, Brasil;

${ }^{2}$ Universidade de São Paulo, Faculdade de Medicina, Hospital das Clínicas, Divisão de Geriatria, São Paulo SP, Brasil;

${ }^{3}$ Universidade de São Paulo, Faculdade de Medicina, Hospital de Clínicas, Departamento de Neurologia, Centro de Dor Interdisciplinar, São Paulo SP, Brasil;

«Universidade de São Paulo, Faculdade de Medicina, Hospital das Clínicas, Divisão de Odontologia, Grupo de Dor Orofacial, São Paulo SP, Brasil;

${ }_{5}^{5}$ nniversidade de São Paulo, Faculdade de Medicina, Hospital das Clínicas, Divisão de Geriatria, Núcleo de Apoio à Pesquisa em Geriatria e Gerontologia São Paulo SP, Brasil;

${ }^{6}$ Universidade de São Paulo, Faculdade de Medicina, Hospital de Clínicas, Departamento de Neurologia, São Paulo SP, Brasil.
}

Correspondence: Silvia R. D. T. Siqueira; R. Maria Candida, 135;02071-010

São Paulo SP, Brasil; E-mail: silviadowgan@hotmail.com

Support: This work was supported by National Council of Scientific Researches - Brazil (160938/2013-9).

Conflict of interest: There is no conflict of interest to declare.

Received 04 June 2018; Received in final form 12 August 2018; Accepted 13 August 2018. 
Other findings also consider a possible relationship between pressure levels and sensory changes ${ }^{13}$.

Although there is evidence of sensory decline in the elderly, to our knowledge, there is no longitudinal study that has investigated this aspect. Moreover, sensitivity abnormalities are involved in several chronic diseases that affect the elderly, and the use of chronic medication is common. The association between sensory thresholds and chronic illnesses has not been investigated before.

Thus, the objectives of this study were to evaluate the sensory characteristics of elderly patients from a geriatric service and to investigate associations of these findings with clinical aspects.

\section{METHODS}

This was a descriptive longitudinal study (cohort) conducted at the Faculty of Medicine in the Hospital das Clínicas, University of São Paulo, Brazil. The study period was over 24 months starting in June 2014 and ending in June 2016. All participants were informed about the purposes of the study and signed a free and informed consent form. The protocol was approved by the local ethics committee - CAPPesq - Comitê de Ética do Hospital das Clínicas da FMUSP (224.149).

\section{Participants}

We enrolled 36 healthy participants of both sexes in this longitudinal study. These individuals returned for the second evaluation after one year, with only 24 participants $(66.7 \%)$ returning for the third and final annual evaluation. They were part of the healthy ambulatory elderly from the Geriatric Service of the Hospital das Clínicas in the Medical School of the University of São Paulo.

Inclusion criteria comprised individuals aged 60 years or older, who were healthy-according to a geriatric assessment-or who had any of the following high-incidence morbidities in the elderly: hypertension, type II diabetes mellitus, osteoporosis, osteoarthritis, dyslipidemia and hypothyroidism, as long as they were asymptomatic and controlled through the use of medicines.

Exclusion criteria were: not agreeing in participate in the study, chronic pain, malignant tumor, acute cardiovascular disease, rheumatological, neuroendocrine or neurodegenerative illnesses, gustative or olfactory abnormalities, allergies or nasal obstruction. All participants were evaluated by geriatricians to diagnose these conditions. The following instruments were used and evaluations performed: clinical evaluation (data from medical records including old and new diseases, medication, examinations - hemogram, glycemia and cholesterol, measurements of arterial pressure and cardiac frequency), the Mini-Mental State Exam, and quantitative sensory testing.

\section{Quantitative sensory testing}

All participants underwent a standardized protocol of quantitative sensory testing for the evaluation of somatosensory thresholds ${ }^{14}$, which included olfactory, gustative, thermal (cold and warm), mechanical (tactile and vibration) and pain thresholds. The corneal reflex was also investigated ${ }^{6}$.

The regions evaluated were the face (maxillary territory) and hand. All participants were seated in a silent room for evaluation by a single researcher. They were told to keep their eyes closed during the tests and inform the researcher when they perceived the stimulus by answering 'yes' or 'no', and in which stimulus modality (olfactory, gustative, mechanical and pain thresholds) it was perceived. Thermal thresholds were evaluated by an electronic system that included a button to be pushed when the stimulus was detected. Only the researcher knew the order of stimuli ${ }^{6}$. The stimuli were applied at small intervals of at least a minute, which corresponded with the preparation of the next stimulus to be applied.

The first test was the olfactory threshold, evaluated using isopropanol solutions $(0.05 \%, 0.2 \%, 1 \%, 3 \%, 7 \%, 13 \%$ and $20 \%)$ in polyethylene bottles mixed with distilled water ${ }^{14,15,16}$. The threshold was determined when the participant detected the smell three consecutive times.

The second test was the taste threshold: sour (citric acid): $0.00032 \mathrm{M}$; $0.001 \mathrm{M}$; 0.0032 M; 0.01 M; 0.032 M; sweet (glucose): 0.01 M; 0.032 M; 0.1 M; 0.32 M; 1.0 M; bitter (urea): 0.1 M; $0.32 \mathrm{M} ; 1.0 \mathrm{M} ; 3.2 \mathrm{M} ; 10.0 \mathrm{M}$ and salty (sodium chlorate): 0.01 M; 0.032 M; 0.1 M; 0.32 M. They consisted of a drop of substance applied to the tongue, mixed with one drop of distilled water, in increasing concentrations until detection.

The thermal (cold and warm) thresholds were evaluated with the MSA thermos test device (Somedic, Sweden). The equipment has a thermode with a $9 \mathrm{~mm}$ X $9 \mathrm{~mm}$ flat surface that starts from a temperature of $32^{\circ} \mathrm{C}$. It increases in increments of $1^{\circ} \mathrm{C}$, up to $40^{\circ} \mathrm{C}$ ( for warmth detection) or decreases by $1{ }^{\circ} \mathrm{C}$, down to $10^{\circ} \mathrm{C}$ ( for cold detection) $)^{5,17}$. Five measurements were made in each modality to obtain the mean threshold.

Tactile thresholds were obtained by von Frey filaments in an electronic device (IITC, Woodland Hills, CA, USA). Three measurements were made to obtain the mean threshold. Vibration thresholds were obtained with a vibrameter electric device (Somedic, Sweden). This has a flat surface of $1 \mathrm{~cm}^{2}$ and the stimulus was increased or decreased in $1 \mathrm{~Hz}$ steps. The vibration threshold was tested on the face region, to systematize the protocol, in order to compare different evaluated areas, as it had been proven to show differences in a previous study ${ }^{6}$. The participant had to indicate when they detected the appearance or disappearance of the stimulus, and the mean was considered for the analysis.

Pain thresholds were evaluated with a disposable needle in an electronic device (IITC, USA). The participant indicated when they detected the stimulus; three measurements were made and the mean was considered in the analysis. 
The corneal reflex was evaluated with a $0.5 \mathrm{~mm}$ von Frey filament.

\section{Statistical analysis}

The initial descriptive analysis was performed and, after the distribution of the variables, was tested with the Kolmogorov-Smirnov and Shapiro-Wilk test. The qualitative characteristics of the patients were described using absolute and relative frequencies. The quantitative characteristics, laboratory tests and sensitivity measurements were described according to the period of evaluation with the use of summary measures (minimum, maximum, mean, standard deviation and median) and compared using the Friedman test across the time periods, followed by multiple nonparametric comparisons for longitudinal data or analysis of variances with repeated measurements.

Sensory abnormalities were investigated in the comparison between the periods of evaluation, as a longitudinal design. Changes in sensitivity measurements were analyzed according to the presence of each morbidity using Mann-Whitney tests. Analyses were performed using the IBM-SPSS for Windows software version 20.0 and the tables were created using Microsoft-Excel 2003 software. The analyses were performed with significance level of $5 \%$.

\section{RESULTS}

\section{General characteristics of the sample}

Of the 36 participants included in the study, 25 (69.4\%) were women and the average age was $71.6 \pm 5.6$ years. None were smokers. Of the participants who completed the evaluations, $24(66.6 \%)$ were women with average age $72.2 \pm 5.6$ years. The prevalence of previous morbidities was $69.4 \%$ ( $\mathrm{n}=$ 25 elderly), and dyslipidemia was the most common (33.3\%) (Table 1). The average height was $1.60 \mathrm{~m} \pm 0.09 \mathrm{~m}$ and the average weight was $66.40 \mathrm{~kg} \pm 13.4 \mathrm{~kg}$ in the initial evaluation. Demographic data are shown in Table 1. There was no statistical difference in these variables, neither in blood pressure nor heart rate, between the evaluations. There was no statistical difference between the initial Mini-Mental State Exam scores (29.14 \pm 1.13$)$, after one year $(28.85 \pm 1.40)$ or after two years $(28.63 \pm 1.90)(\mathrm{p}=0.265)$.

In the evaluation of laboratory blood tests performed in this cohort, there were no significant changes $(p>0.05)$ except for the reduction of mean corpuscular volume (MCV) at each evaluation $(\mathrm{p}<0.001)$ and the significant increase in mean corpuscular hemoglobin concentration (MCHC) $(\mathrm{p}<$ 0.001) (Table 2). The MCV decreased statistically at each evaluation ( $p<0.05$ ), whereas the MCHC increased from baseline at one year and two years $(\mathrm{p}<0.001)$, but between year one to year two, there was a statistically significant reduction of $\operatorname{MCHC}(\mathrm{p}=0.015)$.
Table 1. Demographic profile, morbidities and medications used in the initial evaluation of this sample $(n=36)$

\begin{tabular}{|c|c|c|c|}
\hline Variable & $n$ & $\%$ & $p$-value \\
\hline \multicolumn{4}{|l|}{ Sex } \\
\hline Female & 25 & 69.4 & 0.676 \\
\hline Male & 11 & 30.6 & \\
\hline \multicolumn{4}{|l|}{ Marital status } \\
\hline Single & 4 & 11.1 & \\
\hline Married & 22 & 61.1 & 0.864 \\
\hline Divorced & 1 & 2.8 & \\
\hline Widower & 9 & 25.0 & \\
\hline \multicolumn{4}{|l|}{ Occupation } \\
\hline Housewives & 3 & 8.3 & \\
\hline Retired & 26 & 72.2 & 0.108 \\
\hline Employed & 7 & 19.4 & \\
\hline \multicolumn{4}{|l|}{ Education } \\
\hline 8 years & 13 & 36.1 & \\
\hline 11 years & 6 & 16.7 & 0.152 \\
\hline 15 years & 17 & 47.2 & \\
\hline \multicolumn{4}{|l|}{ Ethnic group } \\
\hline White & 27 & 75.0 & \\
\hline Black & 1 & 2.8 & 0.007 \\
\hline Asian & 8 & 22.2 & \\
\hline \multicolumn{4}{|l|}{ Consumed alcohol } \\
\hline No & 27 & 75.0 & \\
\hline Weekly & 4 & 11.1 & 0.784 \\
\hline Socially & 5 & 13.9 & \\
\hline \multicolumn{4}{|l|}{ Morbidities } \\
\hline Hypertension & 7 & 19.4 & \\
\hline Diabetes mellitus type II & 5 & 13.9 & \\
\hline Osteoarthritis & 9 & 25.0 & 0.010 \\
\hline Osteoporosis & 4 & 11.1 & \\
\hline Hypercholesterolemia & 12 & 33.3 & \\
\hline Hypothyroidism & 6 & 16.7 & \\
\hline \multicolumn{4}{|l|}{ Number of morbidities } \\
\hline None & 11 & 30.6 & \\
\hline One & 12 & 33.3 & 0.100 \\
\hline Two & 8 & 22.2 & \\
\hline Three & 5 & 13.9 & \\
\hline \multicolumn{4}{|l|}{ Medication } \\
\hline Antihypertensive & 7 & 19.4 & \\
\hline Antiglycemic & 5 & 13.9 & \\
\hline Antiresorptive & 3 & 8.3 & \\
\hline Anti-inflammatory & 6 & 16.7 & 0.006 \\
\hline Statins & 10 & 27.8 & \\
\hline Levothyroxyne sodium & 7 & 19.4 & \\
\hline Analgesic & 6 & 16.7 & \\
\hline \multicolumn{4}{|l|}{ Number of medications } \\
\hline None & 15 & 41.7 & \\
\hline One & 6 & 16.7 & 0.216 \\
\hline Two & 7 & 19.4 & \\
\hline Three & 8 & 22.2 & \\
\hline
\end{tabular}


Table 2. Results of MCV and MCHC comparisons between the periods of follow-up.

\begin{tabular}{ccccc}
\hline Variable & \multicolumn{2}{c}{ Comparison } & Value Z & $\mathrm{p}$-value \\
\hline \multirow{3}{*}{$\mathrm{MCV}(\mathrm{fL})$} & Initial - & 1 year & 3.39 & $<0.001$ \\
& Initial - & 2 years & 5.82 & $<0.001$ \\
& 1 year - & 2 years & 2.43 & 0.015 \\
& Initial - & 1 year & -5.82 & $<0.001$ \\
$\mathrm{MCHC}^{*}(\mathrm{~g} / \mathrm{dL})$ & Initial - & 2 years & -3.39 & $<0.001$ \\
& 1 year - & 2 years & 2.43 & 0.015
\end{tabular}

Multiple nonparametric comparisons for longitudinal data

*MCV: mean corpuscular volume, MCHC: mean corpuscular hemoglobin concentration.

Figures 1 and 2 show that smell perception, identification of salty, sour and bitter taste, thermal sensitivity to cold on the face, cold thermal sensitivity of the hand, tactile sensitivity of the face, tactile sensitivity of the hand and vibration sensitivity of the face, altered significantly throughout the follow-up ( $\mathrm{p}<0.05$ ). The difference in the sweet evaluation shown in Figure 1 and the difference in the facial pain threshold shown in Figure 2 were not statistically significant. There were no differences in the evaluation of the corneal reflex.

Table 3 shows that the identification of the salty taste, the bitter taste, the thermal sensitivity to cold on the face and hand, the tactile sensitivity of the hand and the vibration sensitivity of the face showed a statistically significant increase after two years compared with the other periods evaluated $(p<0.05)$. The perception of smell and tactile sensitivity of the face increased at each evaluated period $(\mathrm{p}<0.05)$ and the identification of the sour taste increased after two years relative to the baseline $(\mathrm{p}<0.001)$.

Previous morbidities were associated with sensitivity changes in the longitudinal evaluation of the individuals in this sample (Table 4). There were no differences between the groups in the use of medication ( $\mathrm{p}<0.05$, Kruskal-Wallis).

\section{DISCUSSION}

The impact of chronic diseases on human aging is very important. The control of pathological conditions has allowed an increase in survival with quality of life. The role of early diagnosis is indisputable for preventive and curative measures to be established by improving the prognosis and, in this sense, the identification of markers that allow the recognition of disease processes, even before the appearance of clinical symptoms, can become a tool for healthy aging. This study showed evidence of sensitivity changes related to chronic diseases in the elderly population. It was a noninvasive examination and could become a routine preventive evaluation tool.

In the present study, statistically significant differences between the periods of evaluation in this longitudinal design were observed with the salty taste threshold $(p=0.024)$ and bitter taste threshold $(\mathrm{p}=0.001)$, as well as cold threshold on the face ( $p=0.019)$, cold on the hand ( $p=0.004)$, tactile threshold of the hand $(p=0.012)$ and vibratory threshold on the face $(p=0.018)$ being increased after two years compared with the initial evaluation. The olfactory threshold ( $p$ $<0.001)$ and tactile threshold on the face $(\mathrm{p}<0.001)$ showed a progressive increase at each evaluation and the sour taste threshold $(p=0.020)$ increased after two years when compared with the initial evaluation.

The findings described above corroborate previous studies that indicated, through cross-sections, the tendency to increases in these same variables ${ }^{5,6}$. Through this longitudinal (a)

$P<0.001$

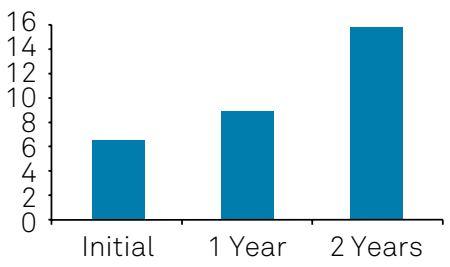

(b)

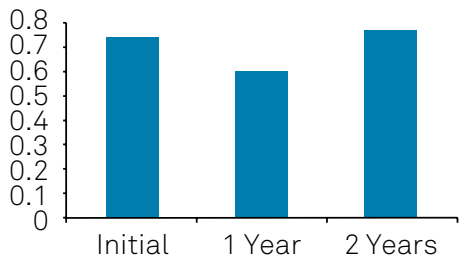

(c)

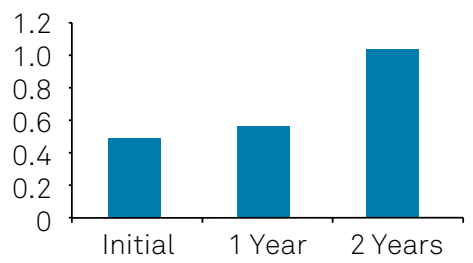

(d)

$$
P=0.020
$$

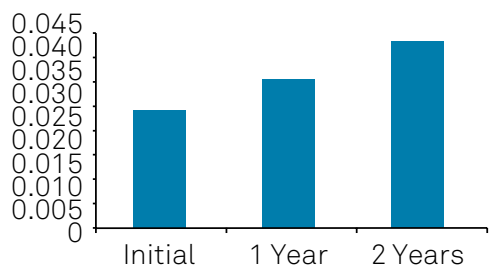

(e)

$P=0.001$

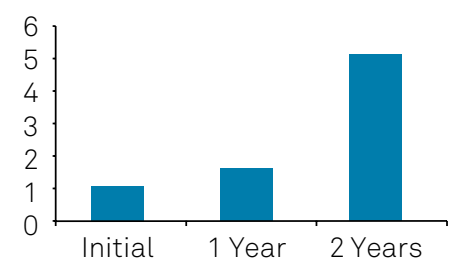

Figure 1. Olfactory and gustative thresholds: comparison among evaluations ( $n=36$ ). (a) Olfactory detection thresholds; (b) Sweet detection thresholds; (c) Salty detection thresholds; (d) Sour detection thresholds; (e) Bitter detection thresholds. Statistical analysis: Friedman test. 
(a)

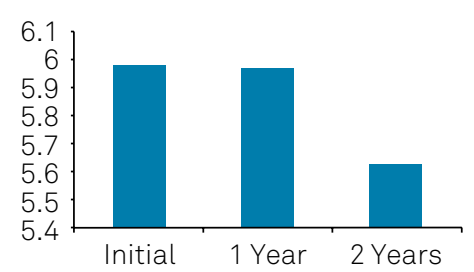

(d)

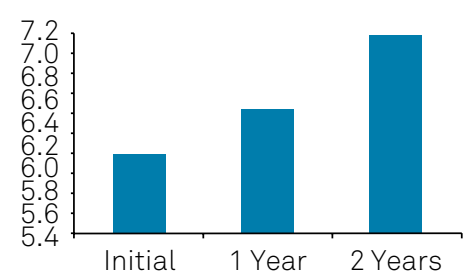

(g)

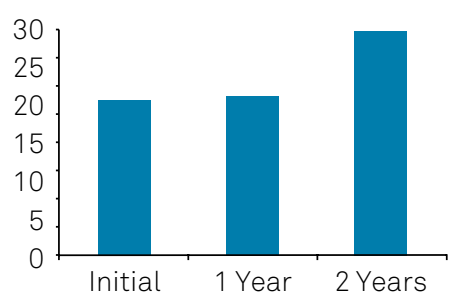

(b)

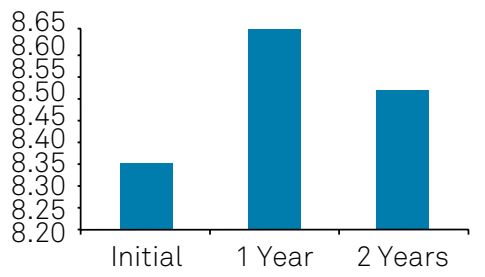

(e)

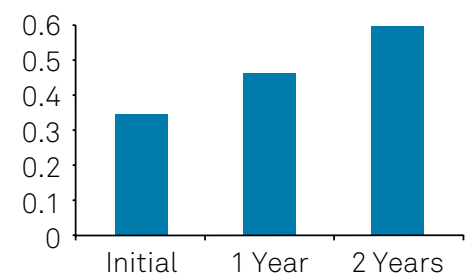

(h)

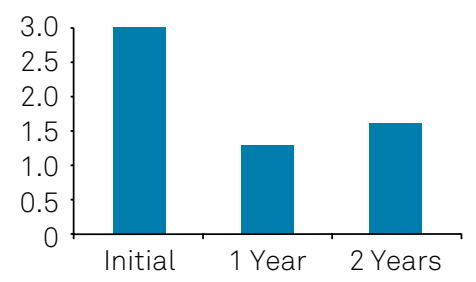

(j) $\quad P=0.962$

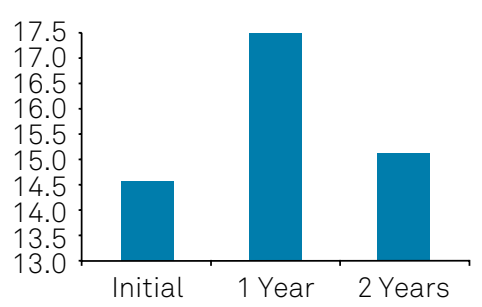

(c)

$P=0.019$

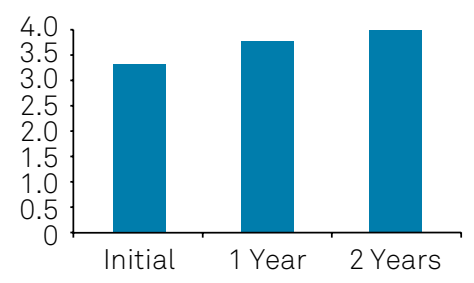

(f)

$$
P=0.012
$$

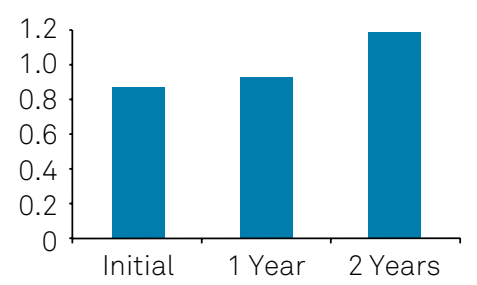

(i)

$$
P=0.534
$$

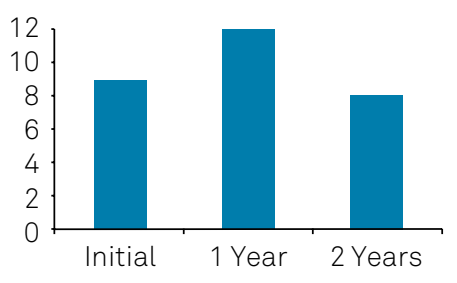

Figure 2. Somatosensory detection thresholds: comparison among evaluations ( $n=36$ ). (a) Warm face detection thresholds; (b) Warm hand detection thresholds; (c) Cold face detection thresholds; (d) Cold hand detection thresholds; (e) Tactile face detection thresholds; (f) Tactile hand detection thresholds; (g) Vibration face detection thresholds; (h) Vibration hand detection thresholds; (i) Pain face detection thresholds; (j) Pain hand detection thresholds. Statistical analysis: Friedman test.

analysis, there was evidence that these thresholds actually increased with aging. The mechanism involves the reduction in number of mitral cells in the olfactory bulb, ${ }^{18}$ peripheral receptors and afferent fibers ${ }^{19,20}$. In addition, inflammation may be involved by triggering apoptosis in sensory neurons ${ }^{21,22}$. Loss of olfactory sensitivity may be related to neurodegenerative diseases such as Alzheimer's disease and Parkinson's disease ${ }^{23}$. In the case of Alzheimer's disease, the alteration results from accumulation of neurofibrillary tangles in central olfactory regions, entorhinal cortex and, especially, the hippocampus ${ }^{10,24}$. It is believed that these cortical structures are the first areas affected by this disease, which causes olfactory disorders to precede cognitive symptoms in these patients ${ }^{25}$. In addition, the entorhinal cortex processes the entry of multiple sensory modalities and its involvement may affect other sensory modalities ${ }^{26}$. In the case of
Parkinson's disease, dopamine depletion impairs the bulbar olfactory neurogenesis that occurs constantly throughout life and is responsible for maintaining olfactory accuracy ${ }^{27}$.

Among the hematological parameters, only the MCV and $\mathrm{MCHC}$ showed alterations: the values of the MCV were reduced ( $p<0.001)$ and the values of MCHC increased ( $p<$ 0.001 ). These parameters suggest the possibility of anemia in the elderly ${ }^{28}$. The scientific literature shows that superficial neuropathy might occur due to the reduction of oxygen supply in the skin when anemia is present ${ }^{29}$; however, there was no diagnosis of this condition in the patients during the study. The immunoscenecence process could be related to the findings of this study ${ }^{30}$.

Hypertensive patients showed higher heat thresholds in the hand $(p=0.031)$ after one year of evaluation and reduction of tactile thresholds in the hand ( $p=0.004$ ) after two years of 
Table 3. Results of the comparisons of the sensitivity measures that changed during the follow-up between the moments of evaluation.

\begin{tabular}{|c|c|c|c|c|}
\hline \multirow[t]{2}{*}{ Variable } & \multicolumn{2}{|c|}{ Comparison } & \multirow{2}{*}{$\begin{array}{c}\text { Value Z } \\
-2.69\end{array}$} & \multirow{2}{*}{$\begin{array}{c}\text { p-value } \\
0.007\end{array}$} \\
\hline & Initial - & 1 year & & \\
\hline \multirow[t]{2}{*}{ Olfactory (\%) } & Initial - & 2 years & -6.86 & $<0.001$ \\
\hline & 1 year - & 2 years & -4.16 & $<0.001$ \\
\hline \multirow{3}{*}{ Salty (mol) } & Initial - & 1 year & 0.00 & $>0.999$ \\
\hline & Initial - & 2 years & -2.79 & 0.005 \\
\hline & 1 year - & 2 years & -2.79 & 0.005 \\
\hline \multirow{3}{*}{ Sour (mol) } & Initial - & 1 year & -1.81 & 0.070 \\
\hline & Initial - & 2 years & -3.33 & $<0.001$ \\
\hline & 1 year - & 2 years & -1.52 & 0.129 \\
\hline \multirow{3}{*}{ Bitter (mol) } & Initial - & 1 year & 0.29 & 0.769 \\
\hline & Initial - & 2 years & -3.38 & $<0.001$ \\
\hline & 1 year - & 2 years & -3.67 & $<0.001$ \\
\hline \multirow{3}{*}{ Cold - Face $\left({ }^{\circ} \mathrm{C}\right)$} & Initial - & 1 year & 1.42 & 0.155 \\
\hline & Initial - & 2 years & -3.18 & 0.001 \\
\hline & 1 year - & 2 years & -4.61 & $<0.001$ \\
\hline \multirow{3}{*}{ Cold - Hand $\left({ }^{\circ} \mathrm{C}\right)$} & Initial - & 1 year & -0.83 & 0.405 \\
\hline & Initial - & 2 years & -5.19 & $<0.001$ \\
\hline & 1 year - & 2 years & -4.36 & $<0.001$ \\
\hline \multirow{3}{*}{ Tactile - Face $\left(\mathrm{g} / \mathrm{mm}^{2}\right)$} & Initial - & 1 year & -2.55 & 0.011 \\
\hline & Initial - & 2 years & -5.88 & $<0.001$ \\
\hline & 1 year - & 2 years & -3.33 & $<0.001$ \\
\hline \multirow{3}{*}{ Tactile - Hand $\left(\mathrm{g} / \mathrm{mm}^{2}\right)$} & Initial - & 1 year & -0.59 & 0.557 \\
\hline & Initial - & 2 years & -4.16 & $<0.001$ \\
\hline & 1 year - & 2 years & -3.58 & $<0.001$ \\
\hline \multirow{3}{*}{ Vibration - Face $(\mathrm{Hz})$} & Initial - & 1 year & -0.20 & 0.845 \\
\hline & Initial - & 2 years & -3.48 & $<0.001$ \\
\hline & 1 year - & 2 years & -3.28 & 0.001 \\
\hline
\end{tabular}

Multiple non-parametric comparisons for longitudinal data. evaluation when compared with normotensive individuals. Sensitivity alterations have been observed in hypertensive individuals ${ }^{13,31,32}$. One hypothesis is that there is impairment of aortic and cutaneous mechanoreceptors, which leads to hypertension and sensitivity changes. This hypothesis is supported by the fact that degeneration of epithelial sodium channels is involved in the mechanical transduction of many of the mechanoreceptors, including baroreceptors ${ }^{33,34}$. Sensitivity changes may correspond with the clinical sign of hypertension. The use of quantitative devices may be useful in the diagnosis and follow-up of these patients ${ }^{13}$.

Another common morbidity in the population with an impact on sensitivity is type II diabetes mellitus. In this sample, the diabetic elderly presented with a threshold reduction to sweet ( $\mathrm{p}=0.002)$ and bitter ( $\mathrm{p}=0.037)$ tastes, and a threshold increase to facial cold $(p=0.021)$ after one year, and reduction of sour taste thresholds $(p=0.023)$ after two years. In relation to gustatory perception, these findings are contrary to those observed in the literature ${ }^{35,36}$ but may be justified, at least in part, by an increase in the expression of receptors in the taste buds due to the lower supply of sweet foods, part of the diet required in diabetic patients. The increase of thermal thresholds corresponds with other studies and can be related to diabetic neuropathy ${ }^{17,18,37}$.

No sensory differences were observed for osteoporosis and hypothyroidism in the first year of evaluation. However, in the second year, these patients showed a threshold increase to bitter taste $(p=0.018)$ and an increase in the heat thresholds in the hand $(p=0.037)$, respectively. After a year of evaluation, patients with dyslipidemia showed a reduction

Table 4. Association between sensitivity thresholds and previous morbidities.

\begin{tabular}{|c|c|c|c|c|c|}
\hline Morbidities & Sensitivity & Threshold** & Initial & 1 year & 2 years \\
\hline \multirow{2}{*}{ Hypertension } & Warm hand & $\uparrow$ & O & $0.031 *$ & ० \\
\hline & Tactile hand & $\downarrow$ & O & ० & $0.004^{*}$ \\
\hline \multirow{4}{*}{ Diabetes mellitus type II } & Sweet & $\downarrow$ & $0.002^{\star}$ & $\circ$ & ० \\
\hline & Bitter & $\downarrow$ & $0.037 *$ & O & ० \\
\hline & Sour & $\downarrow$ & ० & ० & $0.023 *$ \\
\hline & Cold face & $\uparrow$ & $0.021 *$ & O & ० \\
\hline \multirow{5}{*}{ Osteoarthritis } & Warm hand & $\uparrow$ & $0.047^{\star}$ & o & O \\
\hline & Warm hand & $\downarrow$ & O & $0.017^{\star}$ & $0.036 *$ \\
\hline & Tactile face & $\downarrow$ & ० & o & $0.030 *$ \\
\hline & Tactile hand & $\downarrow$ & ० & ० & $0.036^{*}$ \\
\hline & Olfactory & $\uparrow$ & O & O & $0.007 *$ \\
\hline Osteoporosis & Bitter & $\uparrow$ & ० & ० & $0.018 *$ \\
\hline \multirow{2}{*}{ Hypercholesterolemia } & Vibration face & $\downarrow$ & o & $0.006 *$ & ० \\
\hline & Bitter & $\downarrow$ & O & O & $0.015^{*}$ \\
\hline Hypothyroidism & Warm hand & $\uparrow$ & O & o & $0.037 *$ \\
\hline
\end{tabular}

*Mann-Whitney Test; O: $p>0.05 ; \uparrow$ increased; $\downarrow$ decreased. 
in facial vibration thresholds $(\mathrm{p}=0.006)$ and after two years reduced thresholds to bitter taste $(\mathrm{p}=0.015)$.

Osteoarthritis was associated with increased heat thresholds on the hand $(p=0.047)$ followed by a reduction in these thresholds after one year $(p=0.017)$ and after two years $(p$ $=0.036)$, as well as a reduction in tactile thresholds $(p=0.030$ and $p=0.036)$, and increased olfactory thresholds $(p=0.007)$ when compared with the other participants in this cohort. The mechanism is unknown and may involve chronic inflammation, increased secretion of cytokines and pro-inflammatory mediators, and possible central sensitization, due to the persistence of these processes in these patient ${ }^{38,39}$. Such findings may indicate a possible association between sensory changes and morbidities of high prevalence among the elderly, and further longitudinal studies are necessary to understand this relationship.
The main limitation of this study was the loss of the sample by discontinuation in the evaluations. However, as a complex evaluation performed in healthy volunteers, it provided evidence for sensory loss and associations with chronic illnesses in a pioneer cohort study.

In conclusion, this study showed evidence that suggests sensory loss in several sensory thresholds in aging. This is the first study, to our knowledge, that investigated sensory abnormalities in the elderly, in a longitudinal design. There was also an association of sensory differences and chronic diseases common in the elderly population, for which hypothesized mechanisms have been discussed, but these need further investigation. Sensory abnormalities are clinical parameters that may be useful in patient assessment and the establishment of early preventive attitudes.

\section{References}

1. Christensen K, Doblhammer G, Rau R, Vaupel JW. Ageing populations: the challenges ahead. Lancet. 2009 Oct;374(9696):1196-208. https://doi.org/10.1016/S0140-6736(09)61460-4

2. Niccoli T, Partridge L. Ageing as a risk factor for disease. Curr Biol. 2012 Sep;22(17):R741-52. https://doi.org/10.1016/j.cub.2012.07.024

3. Fraga MF, Esteller M. Epigenetics and aging: the targets and the marks. Trends Genet. 2007 Aug;23(8):413-8. https://doi.org/10.1016/j.tig.2007.05.008

4. Kirkwood TB. Understanding the odd science of aging. Cell. 2005 Feb;120(4):437-47. https://doi.org/10.1016/j.cell.2005.01.027

5. Heft MW, Robinson ME. Age differences in orofacial sensory thresholds. J Dent Res. 2010 Oct;89(10):1102-5. https://doi.org/10.1177/0022034510375287

6. Silva LA, Lin SM, Teixeira MJ, Siqueira JT, Jacob Filho W, Siqueira S. Sensorial differences according to sex and ages. Oral Dis. 2014 Apr;20(3):e103-10. https://doi.org/10.1111/odi.12145

7. Lautenbacher S, Kunz M, Strate P, Nielsen J, Arendt-Nielsen L. Age effects on pain thresholds, temporal summation and spatial summation of heat and pressure pain. Pain. 2005 Jun;115(3):410-8. https://doi.org/10.1016/j.pain.2005.03.025

8. Lin YH, Hsieh SC, Chao CC, Chang YC, Hsieh ST. Influence of aging on thermal and vibratory thresholds of quantitative sensory testing. J Peripher Nerv Syst. 2005 Sep;10(3):269-81. https://doi.org/10.1111/j.1085-9489.2005.10305.x

9. Doty RL. Olfaction in Parkinson's disease. Parkinsonism Relat Disord. 2007;13(13 Suppl 3):S225-8. https://doi.org/10.1016/S1353-8020(08)70006-3

10. Wilson RS, Arnold SE, Schneider JA, Boyle PA, Buchman AS, Bennett DA. Olfactory impairment in presymptomatic Alzheimer's disease. Ann N Y Acad Sci. 2009 Jul;1170(1170):730-5. https://doi.org/10.1111/j.1749-6632.2009.04013.x

11. Chao CC, Hsieh SC, Yang WS, Lin YH, Lin WM, Tai TY et al. Glycemic control is related to the severity of impaired thermal sensations in type 2 diabetes. Diabetes Metab Res Rev. 2007 Nov;23(8):612-20. https://doi.org/10.1002/dmrr.734

12. Arap A, Siqueira SRDT, Silva CB, Teixeira MJ, Siqueira JT. Trigeminal pain and quantitative sensory testing in painful peripheral diabetic neuropathy. Arch Oral Bio. 2010 Jul;55(7):486-93. https://doi.org/10.1016/j.archoralbio.2010.03.021

13. Viggiano A, Zagaria N, Passavanti MB, Pace MC, Paladini A, Aurilio C et al. New and low-cost auto-algometry for screening hypertensionassociated hypoalgesia. Pain Pract. 2009 Jul-Aug;9(4):260-5. https://doi.org/10.1111/j.1533-2500.2009.00287.x
14. Siviero M, Teixeira MJ, Siqueira JT, Siqueira SR. Somesthetic,gustatory, olfactory function and salivary flow in patients with trigeminal neuropathic pain. Oral Dis. 2010;(16):482-7. https://doi.org/10.1111/j.1601-0825.2010.01660.x

15. Siqueira SR, Nóbrega JC, Teixeira MJ, Siqueira JT. Olfactory threshold increase in trigeminal neuralgia after balloon compression. Clin Neurol Neurosurg. 2006 Dec;108(8):721-5. https://doi.org/10.1016/j.clineuro.2005.12.007

16. Siviero M, Alvarez FK, Okada M, Teixeira MJ, de Siqueira JT, de Siqueira SR. Facial sensibility of patients with trigeminal neuralgias. Clin Neurol Neurosurg. 2011 May;113(4):268-71. https://doi.org/10.1016/j.clineuro.2010.11.012

17. Matos R, Wang K, Jensen JD, Jensen T, Neuman B, Svensson P et al. Quantitative sensory testing in the trigeminal region: site and gender differences. J Orofac Pain. 2011;25(2):161-9.

18. Kovács T. Mechanisms of olfactory dysfunction in aging and neurodegenerative disorders. Ageing Res Rev. 2004 Apr;3(2):215-32. https://doi.org/10.1016/j.arr.2003.10.003

19. Stuart M, Turman AB, Shaw J, Walsh N, Nguyen V. Effects of aging on vibration detection thresholds at various body regions. BMC Geriatr. 2003 Feb;3(3):1. https://doi.org/10.1186/1471-2318-3-1

20. Chang YC, Lin WM, Hsieh ST. Effects of aging on human skin innervation. Neuroreport. 2004 Jan;15(1):149-53. https://doi.org/10.1097/00001756-200401190-00029

21. Fotin-Mleczek M, Henkler F, Samel D, Reichwein M, Hausser A, Parmryd I et al. Apoptotic crosstalk of TNF receptors: TNF-R2induces depletion of TRAF2 and IAP proteins and accelerates TNF-R1-dependent activation of caspase-8. J Cell Sci. 2002 Jul;115(Pt 13):2757-70.

22. Di lorio A, Cherubini A, Volpato S, Sparvieri E, Lauretani F, Franceschi $C$ et al. Markers of inflammation, vitamin E and peripheral nervous system function: the InCHIANTI study. Neurobiol Aging. 2006 Sep;27(9):1280-8. https://doi.org/10.1016/j.neurobiolaging.2005.07.004

23. Doty RL. The olfactory system and its disorders. Semin Neurol. 2009 Feb;29(1):74-81. https://doi.org/10.1055/s-0028-1124025

24. Wilson RS, Arnold SE, Schneider JA, Tang Y, Bennett DA. The relationship between cerebral Alzheimer's disease pathology and odour identification in old age. J Neurol Neurosurg Psychiatry. 2007 Jan;78(1):30-5. https://doi.org/10.1136/jnnp.2006.099721

25. Li KZ, Lindenberger U. Relations between aging sensory/ sensorimotor and cognitive functions. Neurosci Biobehav Rev. 2002 Nov;26(7):777-83. https://doi.org/10.1016/S0149-7634(02)00073-8 
26. Cushman LA, Stein K, Duffy CJ. Detecting navigational deficits in cognitive aging and Alzheimer disease using virtual reality. Neurology. 2008 Sep;71(12):888-95. https://doi.org/10.1212/01.wnl.0000326262.67613.fe

27. Ross GW, Petrovitch H, Abbott RD, Tanner CM, Popper J, Masaki, et al. Association of olfactory dysfunction with risk for future Parkinson's disease. Ann Neurol. 2008 Feb;63(2):167-73. https://doi.org/10.1002/ana.21291

28. Barbosa DL, Arruda IK, Diniz AS. Prevalência e caracterização da anemia em idosos do Programa de Saúde da Família. Rev Bras Hematol Hemoter. 2006;28(4):288-92. https://doi.org/10.1590/S1516-84842006000400014

29. Besné I, Descombes C, Breton L. Effect of age and anatomical site on density of sensory innervation in human epidermis. Arch Dermatol. 2002 Nov;138(11):1445-50. https://doi.org/10.1001/archderm.138.11.1445

30. Ostan R, Bucci L, Capri M, Salvioli S, Scurti M, Pini E et al. Immunosenescence and immunogenetics of human longevity. Neuroimmunomodulation. 2008;15(4-6):224-40. https://doi.org/10.1159/000156466

31. Ghione S. Hypertension-associated hypalgesia. Evidence in experimental animals and humans, pathophysiological mechanisms, and potential clinical consequences. Hypertension. 1996 Sep;28(3):494-504. https://doi.org/10.1161/01.HYP.28.3.494

32. Nascimento Rebelatto M, Alburquerque-Sendín F, Guimarães JF, Salvini TF. Pressure pain threshold is higher in hypertensive compared with normotensive older adults: A case- control study. Geriatr Gerontol Int. 2017 Jun;17(6):967-72. https://doi.org/10.1111/ggi.12824

33. Chapleau MW, Li Z, Meyrelles SS, Ma X, Abboud FM. Mechanisms determining sensitivity of baroreceptor afferents in health and disease. Ann NY Acad Sci. 2001 Jun;940(940):1-19.

34. Tavernarakis N, Driscoll M. Degenerins. At the core of the metazoan mechanotransducer? Ann N Y Acad Sci. 2001 Jun;940(940):28-41.

35. Gondivkar SM, Indurkar A, Degwekar S, Bhowate R. Evaluation of gustatory function in patients with diabetes mellitus type 2. Oral Surg Oral Med Oral Pathol Oral Radiol Endod. 2009 Dec;108(6):87680. https://doi.org/10.1016/j.tripleo.2009.08.015

36. Naka A, Riedl M, Luger A, Hummel T, Mueller CA. Clinical significance of smell and taste disorders in patients with diabetes mellitus. Eur Arch Otorhinolaryngol. 2010 Apr;267(4):547-50. https://doi. org/10.1007/s00405-009-1123-4

37. Løseth S, Stålberg E, Jorde R, Mellgren SI. Early diabetic neuropathy: thermal thresholds and intraepidermal nerve fibre density in patients with normal nerve conduction studies. J Neurol. 2008 Aug;255(8):1197-202. https://doi.org/10.1007/s00415-008-0872-0

38. Attur M, Statnikov A, Aliferis CF, Li Z, Krasnokutsky S, Samuels J et al. Inflammatory genomic and plasma biomarkers predict progression of symptomatic knee OA (SKOA). Osteoarthritis Cartilage. 2012;20 Suppl 1:S34-5. https://doi.org/10.1016/j.joca.2012.02.562

39. Sohn DH, Sokolove J, Sharpe O, Erhart JC, Chandra PE, Lahey LJ et al. Plasma proteins present in osteoarthritic synovial fluid can stimulate cytokine production via Toll-like receptor 4. Arthritis Res Ther. 2012 Jan;14(1):R7. https://doi.org/10.1186/ar3555 